\title{
Early intervention specialized services: eligibility and multiprofessional work
}

\author{
Isabela Rocha Izidoro ${ }^{1}$ \\ https://orcid.org/0000-0003-3612-2387 \\ Dayana Insfran Jorcuvich ${ }^{1}$ \\ https://orcid.org/0000-0002-0528-639X \\ Veronica Aparecida Pereira ${ }^{1}$ \\ https://orcid.org/0000-0002-9051-7550 \\ Olga Maria Piazentin Rolim Rodrigues ${ }^{2}$ \\ https://orcid.org/0000-0002-5332-256X
}

Universidade Federal da Grande Dourados - UFGD, Dourados, Mato Grosso do Sul, Brasil.

2 Universidade Estadual Paulista Júlio de Mesquita Filho - Campus de Bauru, Bauru, São Paulo, Brasil.

Conflict of interests: Nonexistent

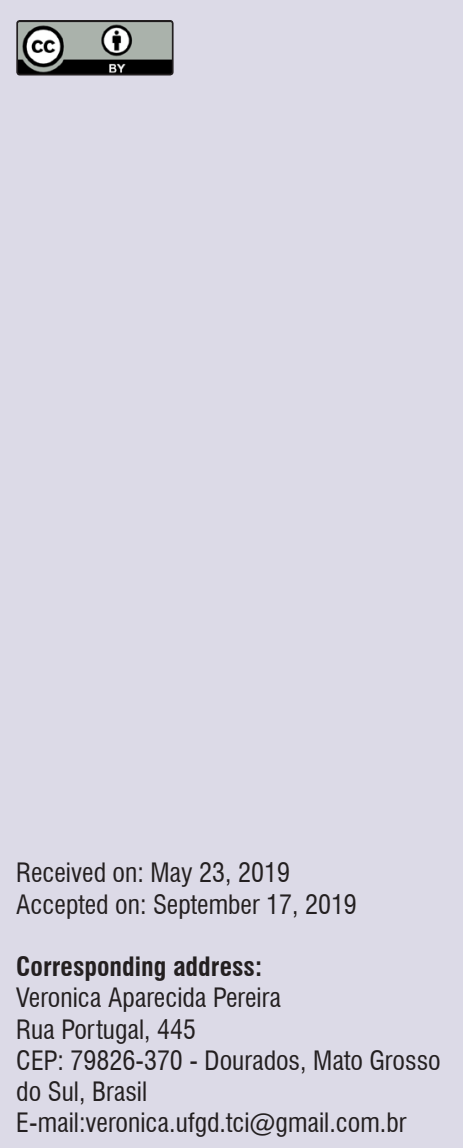

\section{ABSTRACT}

Objective: to characterize the early intervention services offered by the Association of Parents and Friends of People with Intellectual Disability (APAE, its Portuguese acronym) in the state of Mato Grosso do Sul.

Methods: out of the 56 institutions considered, 33 confirmed the existence of early Intervention services and received, via e-mail, a protocol for the characterization of services. Ten of these protocols were answered by the person responsible for the institution. The data were charted and analyzed by means of descriptive statistics and cartographic representation of Mato Grosso do Sul.

Results: the studied institutions are present in much of the territorial extension of the state. However, a large central area, with relevant population density, still lacks coverage. The most frequently used term to characterize the service was "early stimulation". As their target public, the institutions prioritize syndromic, malformed and premature babies, as well as those at social risk, in the age range zero to three years $(60 \%)$, who are referred by the health services and undergo screening. All institutions have a multi-professional team, with at least four different professionals, in inter- or transdisciplinary practice; their intervention plan is elaborated with and for the family.

Conclusion: considering the importance of early intervention along with the families, it is important to highlight the urgency of continuing education with the region's institutions for the services to be offered.

Keywords: Early Stimulation; Child Development; Special Education 


\section{INTRODUCTION}

In early childhood, specifically, some authors propose the understanding of the newborn's development from bidirectional perspectives, in which both the adult and the child participate together ${ }^{1-3}$. In this perspective, it is understood that the relations established in the context of the child and their relatives, the quality of stimulation and the reciprocity in relationships are capable of creating environments that work as protective factors. In the child-adult interaction process, both play important and active roles, and it is of crucial relevance to consider the bidirectional nature of their interaction ${ }^{1}$ and the developmental changes that take place continuously and dynamically through time ${ }^{2}$.

Although the children may present at birth conditions that require additional care, their social context is not always appropriately structured to offer them opportunities for their development. It is understood that it is always possible to teach the children, even when they have some deficiency, risk factor or vulnerability. The Early Intervention Programs, by means of professional teams of the many specialties and along with the families, aim at developing strategies to help these families to be strengthened in face of the challenges of providing a healthy development for the children. In this picture, the specialized services made available at institutions and/or specific healthcare centers, such as those offered by the Association of Parents and Friends of People with Intellectual Disability (APAE, its Portuguese acronym), Pestalozzi and other organizations, are of great relevance.

Factors inherent to the baby, such as prematurity, low birth weight, presence of congenital syndromes or malformations, maternal and environmental factors (as little schooling, low family income, negligence, domestic violence, among others), are characterized as risk factors for child development ${ }^{4-7}$. Identifying the risk and protective factors related to each child's reality aids in planning early intervention programs that best suit and meet that child's reality. Studies have highlighted the need that early intervention programs be established to minimize the effects of the risk factors identified ${ }^{8-11}$.

Early intervention is characterized as an intervention service carried out multi-professionally with babies and children with identified risk. Its goal is to enable a better development by means of attention given to the specific needs of each child, being even potentially capable of recovering possible delays observed in relation to the developmental milestones and making these children's family receptivity easier ${ }^{11}$.

In Brazil, the first guidelines regulating this type of service were the Educational Guidelines for Early Stimulation, developed in 1995 by the Department of Special Education ${ }^{12}$, subordinate to the Ministry of Education and Sports. The guidelines advocated that the service, called early stimulation at the time, should be able to care for the needs of children with some type of deficiency between the ages of zero and three years. The main goal of the service would then be to include these children and prepare them to enter the Special Education Program when due age was reached.

Among the activities that composed this proposal, were: the detection and evaluation of the needs of children eligible for the program and the intervention, which would be the availability of necessary environmental resources so that the intervention process could take place. The early stimulation programs should raise the abilities and potentialities of each child, in order for the intervention to be optimized, taking the risk and protective factors involving each child into account ${ }^{12}$.

The early stimulation programs could happen either unifocally or multifocally. The unifocal approach is focused on the child's development, whereas the multifocal one deals with the environment as well, addressing other themes related to the child development. According to the guideline itself, the multifocal approach would be the most effective. It is worth emphasizing that the abovementioned guideline had already called attention to the need of a team that worked transdisciplinarily ${ }^{12}$.

The first early intervention proposals developed by the Brazilian Guidelines ${ }^{12}$ remained until 2016. The new guideline, a renewal of the previous one, is focused on the care given to children with neuropsychomotor development delay, and it aims at offering guidance to multiprofessional teams specifically for the care of children between zero and three years old ${ }^{11}$, although the international scene points to such need until they are five or six years old $^{13}$. The intervention planning, based on the families' needs, must happen preferentially in the first three years of life, as it is the period of greater neural plasticity, favoring developmental gains. The early intervention programs in Brazil must have their attention turned to health, broadening both the look and the responsibility of the professionals in the area in face of the development and learning demands ${ }^{11}$.

In this perspective, the focus of early intervention turns to the planning of activities based on each child's 
and theirs family's functioning. Hence, there is the need to involve the relatives, seeking to integrate the intervention with the daily activities (feeding, dressing, moving about, and acquiring concepts). Going beyond behavioral acquisition, its function in the family routine and daily life activities must be understood as a means of promoting autonomy ${ }^{13}$.

Hughes-Scholes and Gavidia-Payne ${ }^{14}$ indicated that the implementation of routine-based intervention models is essential to improve the behavioral functioning of children with development delay. They also highlighted the importance of family interaction and the performance of tasks at home, as it increases the children's involvement, independence and social relations, as well as the families' satisfaction with daily routines.

The importance of offering early intervention services has been calling the attention of several researchers in the field of child development ${ }^{14-17}$. The authors pointed to the relevance of early diagnosis and intervention, creating the possibility of intervening in advance in development processes that haven't yet been established, which will influence this person's development up until adult life, due to genetic and organic factors (neuroplasticity).

Even with the attempt to articulate public policies with the purpose of strengthening the early intervention practices, there isn't in Brazil a single service responsible for coordinating these programs ${ }^{18}$. The healthcare services that should articulate it so as to offer an interdisciplinary and continuous care end up not doing so because of public health service organization issues. Thus, even though early intervention may be offered in other services, APAE is still seen as a reference, due to its history of care and services being given to the people with disability or important development delay.

The early Intervention (EI), in its turn, must be centered on the family, having as premise its strengths, desires and needs. The professionals will act as partners, broadening the family's reach to the development of abilities in various contexts, so that as many moments as possible may be well used for directing the family to the child's functional behaviors in their environment ${ }^{19}$

In a theoretical-practical relation, bidirectional and co-participative development theories ${ }^{1-3}$ have highlighted the importance of the family in the context of early intervention, which takes on the active protagonist role, being made capable by the El professionals to play such role. When the intervention context is extended beyond the clinical context, in which the child is cared for by specialized health professionals, the chances of the learnings being more effective and functional for the child's routine are increased ${ }^{16}$.

Another important characteristic regarding EI service organization refer to the team's constitution and mode of organization. Consensually, there are three team characterization types: the multidisciplinary, the interdisciplinary, and the transdisciplinary. The multidisciplinary is characterized by different professionals working along at the same time, but individually and independently. The second one, the interdisciplinary, presents the same characteristics as the first one, but with exchange of information among these professionals. As for the transdisciplinary, indicated by the authors as the best option for El services, is characterized by the fact that the professionals develop the intervention plan together with the family, focusing on the child's and the family's needs and functioning. Such intervention is carried out by all professionals involved, as well as by the family, recalling the concept of the importance of the family participating in the $\mathrm{El}^{14}$.

Considering that the early intervention services may be offered at institutions specialized in caring for children with some kind of deficiency and/or development delay, it is necessary to know how these services have been offered and what its coverage is. This contextualization may favor child intervention public policies planning, so that these services may be more encompassing and effective, in order to ensure that a great number of the children in a situation of risk, deficiency and/or vulnerability may be integrated to the healthcare services as early as possible. For this demand to be met, it is necessary to identify where the services are made available, who offers them, what are the criteria for participating in them, and what are the characteristics of the attention being offered.

Marini, Lourenço and Della Barba ${ }^{20}$, in a literature review, observed that the practices found in early intervention are still turned to child's needs and their evaluation. Only some studies reported an effort on the part of the team to include the family in the process, coming thus closer to what literature indicated as a good intervention practice. According to the authors, the practices are still built around the professional's knowledge, who is seen as the knowledgeable one, while the family stands passive in face of evaluations and interventions.

Given these points, this study aimed at characterizing the early intervention services offered by the 
Association of Parents and Friends of People with Intellectual Disability in Mato Grosso do Sul (MS), and to characterize the team of professionals and their role with the family in caring for the children.

\section{METHODS}

This descriptive study, with both quantitative and qualitative analysis, was approved by the Ethics Committee of the School of Science of the São Paulo State University, evaluation report no. 3.1444.779.

The 56 existing APAEs in Mato Grosso do Sul State, Brazil, were contacted by phone, $33(58.9 \%)$ of which confirmed they offered the El service. The Informed Consent Form (ICF) was sent to these via e-mail, as well as a specific protocol to characterize those services' patients, intervention team and the family's participation. Ten (30.3\%) institutions returned the protocol with the requested information.

The answers obtained through the protocol were organized for analysis in a data bank, primarily as a whole. Afterwards, the answers were organized in categories according to their similarities. The descriptive statistical analysis was carried out, with frequencies and percentages being presented, in addition to the cartographic representation of the early intervention in the State of Mato Grosso do Sul, Brazil.

\section{RESULTS}

Aiming to respond to the objective of the study, the answers from the protocols were organized in subitems, as follows: a) characterization of the El services at the APAEs in the state of Mato Grosso do Sul; b) population cared for and eligibility criteria; c) characterization of the teams and their role with the institution, the children and their relatives.

\section{Characterization of the El services at the APAEs in Mato Grosso do Sul.}

In order to characterize the services, it was sought first to identify how these institutions are distributed in the state, based on the information available at the website of the APAEs Federation in Mato Grosso do Sul. In Figure 1, it is possible to observe that distribution. The areas highlighted in red refer to the municipalities that do not have APAEs in its healthcare service; those that do, are numbered. It is noticeable that APAE is present in most of the municipalities. However, there is a considerable central area where these services are not made available. This also happens in some smaller municipalities in the South of the state.

The APAEs of these municipalities were contacted by phone to identify which of them offered early intervention or stimulation services. In Figure 2, the municipalities highlighted in yellow indicate the absence of such service. Those that remained white confirmed its existence, but did not answer the protocol. The municipalities indicated in green represent those that both have the service and answered the protocol.

Concerning the El services offered by the APAEs in MS, almost $41.9 \%$ of them reported not having them available to the population. All the APAEs reported that the service they offer is called early stimulation (ES). Half of them has been offering the ES service for more than 20 years. As for the others, the practice is more recent: four of them have been offering it for more than five years, and one started offering the service some four or five years ago). 


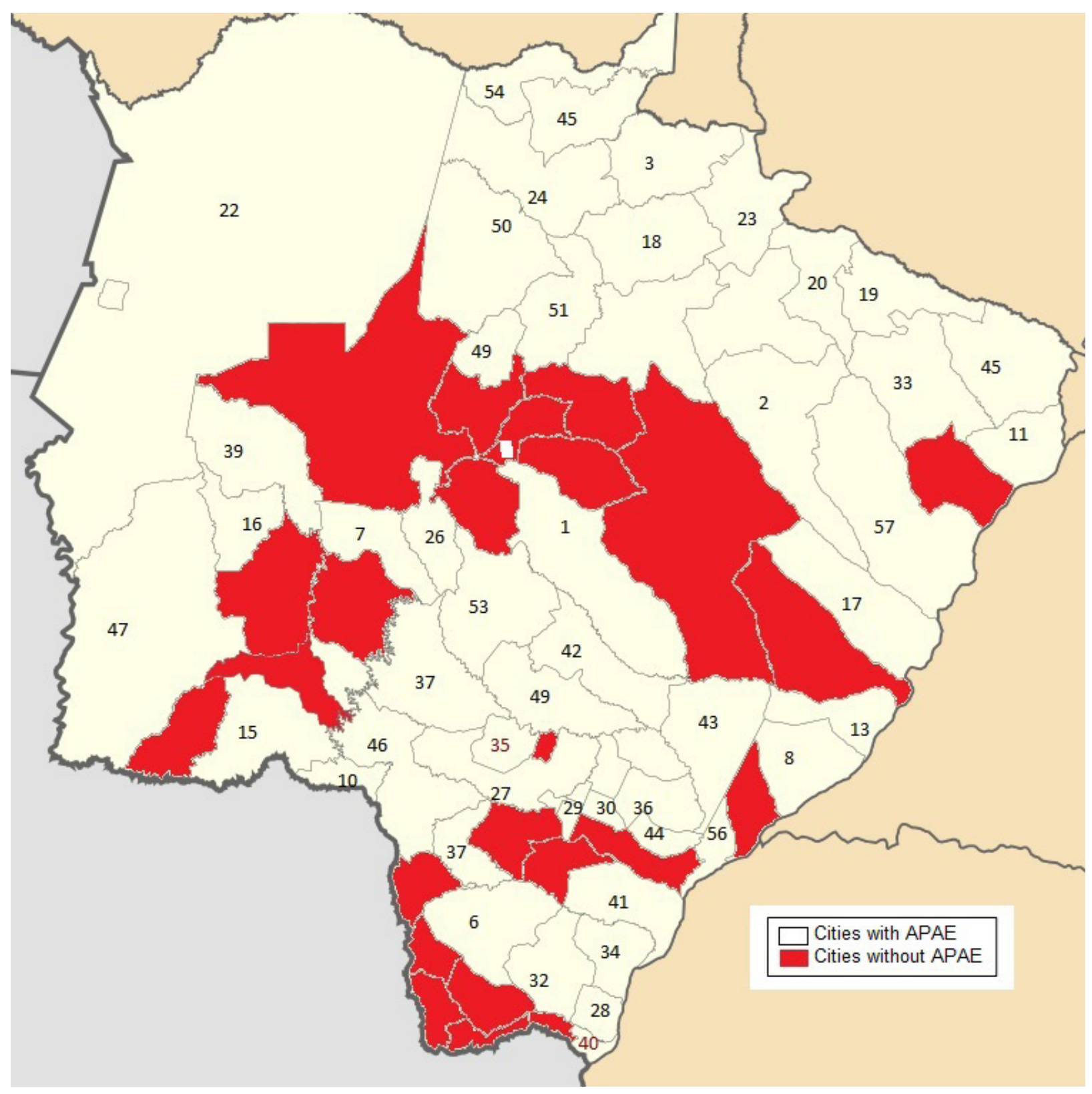

Legend: APAE - Association of Parents and Friends of People with Intellectual Disability.

Source: adapted by the author from a map available at https://pt.wikipedia.org/wiki/Mato_Grosso_do_Sul, with insertions based on the listing of the APAE Federation of the state of Mato Grosso do Sul, Brazil.

Figure 1. Distribution of APAE units throughout the state of Mato Grosso do Sul, Brazil 


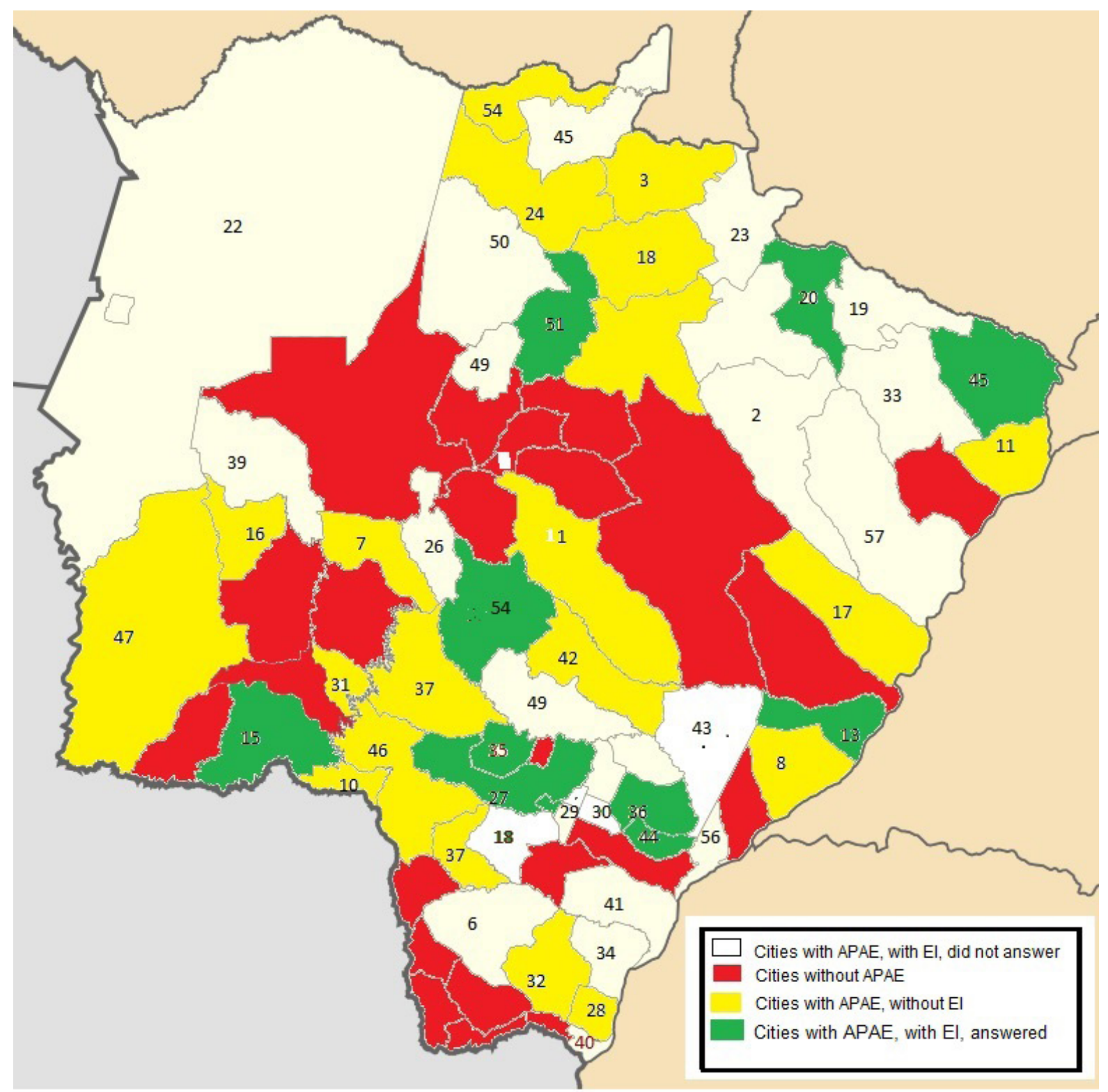

Legend: APAE - Association of Parents and Friends of People with Intellectual Disability; El - early intervention.

Source: adapted by the author from map available at https://pt.wikipedia.org/wiki/Mato_Grosso_do_Sul, with insertions based on the listing of the APAE Federation of the state of Mato Grosso do Sul, Brazil.

Figure 2. Mapping of early intervention or stimulation services in Mato Grosso do Sul, Brazil

\section{Population cared for, referrals, screening, and eligibility criteria}

Regarding their age, out of the 104 children being cared for when this research was carried out, a greater concentration was noticed in the ranges from 13 to 24 months (40.3\%) and from 25 to 36 months (40.3\%). Concerning the possibility of receiving care, with age as the criterion, $60 \%$ of the institutions reported offering care for children between zero and three years old, while $10 \%$ limit themselves to those up to two years old. As for the others, $20 \%$ of the institutions that answered the protocol offer care to children up to five years old, and $10 \%$ offer it to children up to four years old. All the institutions reported that they receive the children upon spontaneous request from their parents, though, there are also referrals from the municipal healthcare service $(70 \%)$ and hospitals or maternities (50\%). Screening is performed by the available professional $(60 \%)$ or multi-professional team (40\%). The baby's age was pointed to as an important factor for eligibility, as those under two years old are prioritized (70\%). Regarding the children's condition, those with syndromes, born preterm or at social risk are eligible. 
Table 1. Characterization of the population, referral, screening and eligibility

Age of the children being cared for while this research was in progress (104)

From 13 to 24 months

Percentage (\%)

From 25 to 36 months

40.3

From 37 to 48 months

29.8

Over 49 months

5.7

\section{Type of referral reported}

Spontaneous requirement

5.3

Municipal healthcare service

Hospitals or maternities

Responsiblefor the screening

Professional available 50

Multi-professional team

\section{Eligibility criteria}

Age under two years old 40

Babies with syndromes, born preterm orat social risk

\section{0}

30

\section{Eligible ages}

Only up to two years old

10

Up to three years old

60

Up to four years old

Up to five years old

Source: elaborated by the author.

\section{Characterization of the teams and their role with the institution, the children and their relatives.}

The data obtained concerning the characteristics and practice of the teams are available in Table 2. There can be noticed that the teams of the institutions participating in the study are made up of 70 professionals from the various fields of work, pedagogy and physiotherapy being represented in greater numbers (13 professionals from each of these fields). The presence of psychologists (11), assistants (10) and speech-language-hearing therapists (10) has also been noticed. Among the specialized physicians, there are psychiatrists, pediatricians, neurologists and neuropediatricians (7), besides nutritionists (3) and occupational therapists (3). The teams defined themselves as interdisciplinary $(50 \%)$ or transdisciplinary $(50 \%)$; in the second case, they referred to the participation of all team members in conducting the cases, with integrated decision-making.
The most frequently cited type of caregiving was centered on the child, weekly followed up by all the professionals in the team (30\%). In the sequence, there were reports of institutions in which the family participates in the weekly medical care $(20 \%)$, with follow-ups by the specialties and a more individualized, child-focused care $(20 \%)$. The family is only included in home practices (10\%). Concerning planning, $60 \%$ of the APAEs reported that the intervention plan is developed by all the professionals in discussion with the family, whereas $30 \%$ had only their team develop it, and $10 \%$ counted on individualized professional work. Lastly, the responding units reported that the activities carried out by the teams are: initial evaluation (70\%), intervention plan and assessment of results (60\%), study group and case discussion $(30 \%)$, and full assessment and intervention process $(30 \%)$. 
Table 2. Team characterization and practice

\begin{tabular}{|c|c|}
\hline & Percentage (\%) \\
\hline \multicolumn{2}{|l|}{ Professionals (70) } \\
\hline Educators (13) & 18.6 \\
\hline Physiotherapists (13) & 18.6 \\
\hline Psychologist (11) & 15.6 \\
\hline Speech-Language-Hearing therapists (10) & 14.3 \\
\hline Social Assistants (10) & 14.3 \\
\hline Physicians (7) & 10.0 \\
\hline Nutritionists (3) & 4.3 \\
\hline Occupational therapists (3) & 4.3 \\
\hline \multicolumn{2}{|l|}{ Type of team } \\
\hline Interdisciplinary & 50 \\
\hline Transdisciplinary & 50 \\
\hline \multicolumn{2}{|l|}{ Type of health care } \\
\hline Weekly, child-focused,by all professionals & 30 \\
\hline Weekly, child- and family-focused, by all specialists & 20 \\
\hline Weekly follow-up of the child, by all professionals & 20 \\
\hline Healthcare given by one or two professionals & 10 \\
\hline Weekly follow-up by some areas & 10 \\
\hline Healthcare at home & 10 \\
\hline \multicolumn{2}{|l|}{ Evaluation and intervention } \\
\hline Planning evaluated and plan carried out with the family & 60 \\
\hline Planning evaluated and plan carried out by the team & 30 \\
\hline Planning made individually by professionals & 10 \\
\hline \multicolumn{2}{|l|}{ Activitiesperformedby the team } \\
\hline Initial assessment & 70 \\
\hline Planning & 60 \\
\hline Study groups and case discussion & 30 \\
\hline Full process & 30 \\
\hline
\end{tabular}

Source: elaborated by the author

\section{DISCUSSION}

Mato Grosso do Sul is a Brazilian State of great territorial extension, where the presence of such an institution of great relevance as APAE, with positive impact on the intervention with children and their families, may be considered a positive aspect, since it encompasses a large portion of the state. However, regarding the offer of early intervention services, the need to invest in establishing and planning actions is visible, so that families may be involved and enabled by the programs. The institutions that did have the early intervention service reported characterizing it as early stimulation. This divergence in names also appears in the literature on the subject, including the Guidelines, which indicates the need of advancements in the present status.
According to the criterion established by the guidelines from the Ministry of Health, which point to prioritizing the care offered to children from birth until three years old, only one of the institutions did not meet the requirements yet. On the other hand, some institutions had extended their care to the five-year-old children, as they were sensitive to the need of continuing the offer of these services during this period, in agreement with what is indicated in literature and by international legislation ${ }^{14}$, going beyond that which is advocated in the national guidelines ${ }^{12,13}$.

Concerning the age of the children under care, it was observed that, in spite of the guidelines pointing to the need of El services until the child is three years old, many children have arrived late to the services. Possibly, the means of referral may need to be reviewed, as it is mostly based on spontaneous 
request, and so ensure the possibility of intersecting services, resulting in referrals by the health professionals for earlier and more preventive interventions. Some hindering factors may include the unfamiliarity of these professionals with the existence of such service, and the relation established by the parents between specialized care and deficiency. When seeking specialized care, the family needs to be aware of the child's needs and the benefits for their development and for the family's health as a whole? .

Only one APAE reported that the El services take place in environments other than the institution - namely, the child's school and the home, when necessary. The importance of offering care in other contexts of the child's development may help the family and other partnersunderstand about the functioning of the abilities planned for their reality, promoting the child's and the family's social adjustment, in addition to ensuring the means for autonomy to be achieved. Thus, the intervention needs to establish functionality between the acquired behaviors and the family's needs.

Regarding the team characteristics, the APAEs reported the presence of professionals with diversified training, making an ample discussion field possible for evaluation and intervention. The presence of the family in the process of screening, planning, intervening and evaluating is already perceived in some institutions. Making this reality more widespread is one of the goals of the early intervention programs, favoring practices focused on the family's potentialities and needs ${ }^{17,19}$. Another positive aspect of the teams is the transdisciplinary model. The transdisciplinary practice is characterized as being more complete in El services, as it includes the family, making the process more functional along with professionals of different areas ${ }^{14}$. Nevertheless, there is a contradiction in understanding this model, for $50 \%$ of the institutions claimed they adhered to it, while only $30 \%$ of them reported the family's participation in the whole care process together with the child. Possibly, the teams still need to be trained for this model to be implemented.

The investment in public policies is of great importance to ensure teams training, thus promoting transdisciplinary practice and family-centered planning and action, the participants being effectively involved.

Among the limitations of this study, there is the fact that part of the sample, which reported having early intervention services in the first stage of the research (via telephone), did not answer the questionnaire (via e-mail), which would have contributed to a better mapping of the El services statewide. Future researches with these institutions, with more active and in-person data gathering, may be more effective. It will need, though, to count with the necessary financial provision, due to the state's great dimensions.

Based on the data reported, it is possible to consider that APAE covers a great portion of the state's territory and is made up of professionals capable of offering specialized attention to those in early childhood. Hence, this study is a contribution in indicating the need of training projects, as well as outspreading throughout the population information on El and its services. As El is offered, family involvement may increase; when they seek early services, risk factors for the development of children in condition of deficiency or vulnerability is either minimized or eliminated, thus, promoting the family's health, in different contexts.

\section{CONCLUSION}

Considering the state's population, the high infant mortality rates, and its emerging demands as a border region with different indigenous ethnicities, it is possible to estimate that a great part of the children and their families would benefit from early intervention programs, which should be, above all, a state public policy, encouraging the municipalities to offer this service.

The APAEs, present in a vast portion of the state, generally count on professionals that could work with early prevention. Procedures, if collaborative, would help enabling families, in the transdisciplinary intervention model, to take on an active role for acquiring skills that communicate directly with different development contexts in which the children are inserted.

\section{REFERENCES}

1. Bronfenbrenner U. Making human beings human: biological perspectives on human development. Sage Publications; Thousand Oaks, CA. 2005.

2. Sameroff AJ. A Unified Theory of Development: a dialectic integration of nature and nurture. Child Dev. 2010;81(1):6-22.

3. Gewirtz JL, Pehlez-Nogueras MBF. Skinner's legacy to human infant behavior and development. Am Psychol Assoc. 1992;47(11):1411-22.

4. Pedrosa C, Caçola P, Carvalhal MIMM. Factors predicting sensory profile of 4 to 18 month old infants. Rev Paul Pediatr. 2015;33(2):160-6. 
5. Cruz DSM da, Cordeiro R dos S, Marques DKA, Silva PE. Hypertensive syndromes and risk factors associated with gestation. J Nurs UFPE / Rev Enferm UFPE. 2017;11(Supp. 10):4254-62.

6. Oliveira C, Castro L, Silva R, Freitas I, Gomes M, Cândida M. Fatores associados ao desenvolvimento global aos 4 e 8 meses de idade corrigida de crianças nascidas prematuras. J Hum Growth Dev J Hum Growth Dev. 2016;26(261):1.

7. Ribeiro DG, Perosa GB, Padovani FHP. Fatores de risco para o desenvolvimento de crianças atendidas em unidades de saúde da família, ao final do primeiro ano de vida: aspectos sociodemográficos e de saúde mental materna. Ciênc. saúde coletiva. 2014;19(1):215-26.

8. Vieira PA, Garcia MEB, Linhares CKMR, Formiga MBM. Influência de fatores de risco no desenvolvimento neuromotor de lactentes pré-termo no primeiro ano de vida. Movimenta. 2011;4(2):83-98.

9. Zajonz R, Müller AB, Valentini NC. A influência de fatores ambientais no desempenho motor e social de crianças da periferia de Porto Alegre. Rev da Educ Física/UEM. 2008;19(2):159-71.

10. Carniel CZ, Furtado MC de C, Vicente JB, Abreu RZ, Tarozzo RM, Cardia SETR et al. Influence of risk factors on language development and contributions of early stimulation: an integrative literature review. Rev. CEFAC. 2017;19(1):109-18.

11. Brasil. Ministério da Saúde. Diretrizes de estimulação precoce: crianças de zero a 3 anos com atraso no desenvolvimento neuropsicomotor. Brasília (DF): Ministério da Saúde; 2016.

12. Brasil. Ministério da Educação. Diretrizes educacionais sobre estimulação precoce: o portador de necessidades educativas especiais. Brasília (DF): Ministério da Educação: Secretaria de Educação Especial; 1995.

13. Carvalho L, Almeida IC, Felgueiras I, Leitão S, Boavida J, Santos PC et al. Práticas recomendadas em intervenção precoce na infância: um guia para profissionais. Coimbra: ANIP, 2016.

14. Hughes-Scholes $\mathrm{CH}, \quad$ Gavidia-Payne $\mathrm{S}$. Development of a routines-based early childhood intervention model. Educ rev. 2016;(59):141-54.

15. Pereira VA, Rodrigues OMPR, Apolonio COR, Barbosa LA. Relato de intervenção precoce: acompanhamento de um bebê com a Síndrome de Prader-Willi. Context Clínicos. 2015;9(1):19-31.
16. Rosi FS. Intervenção precoce $x$ estimulação precoce na clínica com bebês. Tempo psicanal. 2018;50(1):174-93.

17. Marini BPR. As práticas de intervenção precoce no estado de São Paulo. [Dissertação]. São Carlos (SP): Universidade Federal de São Carlos, Programa de Pós-Graduação em Terapia Ocupacional; 2017.

18. Gomes CGS, Souza D das G, Silveira AD, Oliveira IM. Intervenção comportamental precoce e intensiva com crianças com autismo por meio da capacitação de cuidadores. Relato Pesqui. 2017;23(3):377-90.

19. Pimentel JVZ de S. Intervenção focada na família: desejo ou realidade. Lisboa: Secretariado Nacional para a Reabilitação e Integração das Pessoas com Deficiência; 2005.

20. Marini BPR, Lourenço MC, Della Barba PC de S. Systematic literature review on models and practices of early childhood intervention in Brazil Rev Paul Pediatr. 2017;35(4):456-63. 